\title{
Música y psicoanálisis, sonidos y silencios del cuerpo ${ }^{1}$
}

\author{
Music and psychoanalysis, sounds and silence of the body
}

\section{Isabel Calderón-Chavarría²; Álvaro Ledezma-Jiménez ${ }^{3}$; Nancy Quesada- Jiménez $^{4}$; Mónica Valerio-Bogarín ${ }^{5}$; Marianela Villalobos-Ulate ${ }^{6}$}

\begin{abstract}
RESUMEN
En el presente artículo, se desarrollará una investigación bibliográfica, cuya finalidad consiste en mostrar el arte de la música más allá de esta como expresión artística, sino como esta se convierte en la voz de lo que necesita ser dicho en el cuerpo, y por el cuerpo. Así mismo se indagará en aspectos relacionados a la música y su historia, la música como acto primitivo, los componentes que la construyen y los afectos que surgen a partir de ella, además al ser estudiada desde un enfoque psicoanalítico se presenta la música desde los tres registros presentados por Lacan.
\end{abstract}

Palabras clave: Música, psicoanálisis, lenguaje, cuerpo.

\begin{abstract}
In the present article, a bibliographical research will be developed, whose purpose is to show the art of music beyond this as an artistic expression, but as this becomes the voice of what needs to be said in the body, and by the body. Likewise it will be investigated in aspects related to music and its history, music as a primitive act, the components that build it and the affections that arise from it, in addition to being studied from a psychoanalytic approach, music is presented from the three records presented by Lacan.
\end{abstract}

Key Words: Music, psychoanalysis, language, body.

\footnotetext{
${ }^{1}$ Artículo elaborado en el curso Seminario de Temas PS-1033 Lo psicosomático, el cuerpo y la estética, Universidad de Costa Rica, Sede de Occidente, bajo la supervisión de la Licda. Andrea Molina Ovares.

${ }^{2}$ Universidad de Costa Rica. Bachiller en Psicología, candidata a la Licenciatura en Psicología, Sede de Occidente. Costa Rica. Correo electrónico: isacc.rock@hotmail.com

${ }^{3}$ Universidad de Costa Rica Estudiante de psicología, Sede de Occidente. Costa Rica. Correo electrónico: alvaro.ledezma10@outlook.com

${ }^{4}$ Universidad de Costa Rica. Bachiller en Psicología, candidata a la Licenciatura en Psicología, Sede de Occidente. Costa Rica. Correo electrónico: nan3092@ hotmail.com

${ }^{5}$ Universidad de Costa Rica. Bachiller en Psicología, candidata a la Licenciatura en Psicología, Sede de Occidente. Costa Rica. Correo electrónico: mo.valeboga21@gmail.com

${ }^{6}$ Universidad de Costa Rica. Bachiller en Psicología, candidata a la Licenciatura en Psicología Sede de Occidente. Costa Rica. Correo electrónico: marianela.villalobos94@gmail.com

Recepción: 5/6/2018 Aceptación: 18/8/2018.
} 
"El más antiguo, el más verdadero y el más bello órgano de la música, el origen del cual nuestra música debe provenir, es la voz humana.”

Richard Wagner.

\section{Introducción}

La música se encuentra, al igual que el sonido y la voz, en el inconsciente humano. Es una construcción o suplencia de este, no una formación del mismo, puede ser la música un elemento en los sueños como lo son las voces, los silencios incluso las melodías que rondan la cabeza de una persona por días revelando el inconsciente (Destefanis, 2016).

Es la música en cierto punto comparable a los sueños y el análisis de los mismos, en donde tanto una melodía como un sueño son sin significación, pero ambos tratan de decir o crear algo (Destefanis, 2016), y además se pueden llegar a interpretar con respecto a las subjetividades.

De acuerdo con Cruz (2011), el discurso musical tiene su complejidad, donde no se le da un seguimiento al arte musical con el fin de interpretarla de determinada forma, sino para escucharla en la vida y en la clínica, donde es la persona quien sabe de ella, pues está articulada en su historia.

En el análisis se lleva a cabo el ejercicio de la escucha, de lo que se dice y no se dice, y lo que quiere decir ese no decir nada, siendo el analista también creador de música, por medio de la voz, instrumento de sonido y música, que se compone para expresar algo (Destefanis, 2016).

En el presente escrito, se plantea un acercamiento a la música, a partir de la teoría psicoanalítica, sin embargo para esto es necesario establecer varias temáticas que serán los ejes sobre los cuales este trabajo girará. No solo se hará un recorrido histórico de la música, sino que se abarcará desde la pre-historia de la música, es decir eso primitivo que genera en las personas el ser tocadas de una u otra forma por la música, eso primitivo que marca el inicio de lo esencial en el sujeto, el lenguaje. Así mismo, se explicará la forma en la que se compone, o está formada la música, sus elementos más importantes, los cuales hacen que no todo ruido sea música. 
Además, al hablar de eso primitivo que toca, debemos mencionar el efecto de los afectos y la música en el cuerpo. Para finalmente, explicar los tres registros descritos por Lacan vistos y entendidos en la, y desde la, música.

\section{La música como expresión desde lo primitivo: el origen del lenguaje es sonoro}

$\mathrm{Al}$ ahondar en la presencia de la música como origen del ser humano, esta se encuentra presente en dos posturas que se construyen de forma dialéctica: la música da origen a la persona como sujeto y a su evolución como cultura.

\section{Musicalidad y formación del lenguaje humano}

La música marca el inicio del proceso de la formación del ser humano en relación con el otro. El grito y el llanto dan sonoridad a la experiencia de necesitar de otro al estar en incompletud, al instaurarse como ser en falta. Es precisamente por medio del grito que el ser humano en sus primeros meses de vida que busca dar señales de su existencia al otro ser, pues es de esta manera rítmica y vibratoria en la que se da ese desarrollo perinatal, que es a su vez prehistoria y origen, da cuenta de un desarrollo en cual al ser uno con la madre era un ser completo, buscando regresar sin lograrlo a ese estado por medio de lo sonoro (Rodríguez Penagos, 2007).

A partir de esta función de la música es que esta es concebida como una forma primitiva de lenguaje. El grito, el llanto y el balbuceo son sonoridades que dan entrada a la comunicación con el otro, una musicalidad que es pulsión que invoca al otro para que responda a sus demandas (Cruz, 2011; Rodríguez Penagos, 2007).

Por su parte, esta sonoridad comunicativa se comprende desde otras perspectivas como musicalidad innata. Se comprende la comunicación entre el bebé y sus padres a base de ritmos, compases, intervalos, melodías y entonaciones como una capacidad innata del ser humano, una musicalidad biológica que marca su sobrevivencia en el medio (Abello y Ramos, 2009). 
Es por medio de la experiencia de la sonoridad, que el (la) bebé logra apreciar y experimentar las dinámicas emocionales en el proceso de adaptación al medio y de crecimiento, logrando comunicarse por medio de lo sonoro que se expresa no solo en su voz, pues todo el cuerpo entra en la experiencia musical (Abello y Ramos, 2009).

Esta musicalidad que permite la relación con un otro y con el medio se va complejizando desde el llanto, balbuceo hasta palabras que toman significado para el lenguaje articulado en sociedad (Cruz, 2011; Abello y Ramos, 2009). Este proceso de la expresión de la sonoridad que se torna lenguaje se fundamenta en la comunicación del niño (a) con su madre, en donde los patrones de tiempo, atención, voz y gestos son identificados como ritmos que permiten la inserción paulatina a la cultura.

Esta sonoridad que construye el lenguaje no deja de ser parte de él, pues esta es el principio de la escucha de sí mismo, de la escucha a partir de la demanda del cuerpo, del estado en falta. Es esta sonoridad una huella de la sobrevivencia y la relación con el medio (Rodríguez Penagos, 2007). Es por esto que en cada palabra persiste la música, que habla con las formas y las palabras de lo consciente y lo prehistórico.

\section{Musicalidad como lenguaje primitivo}

Aunado a lo anterior, es la musicalidad como ente de adaptación y sobrevivencia ante el medio, en relación con otro, la que da paso a la formación del lenguaje en la especie humana. La música surge primero que la palabra por medio del sonido, el cual se emite al golpear las piedras, al chocar huesos, al soplar a través de los objetos, al gritar, al imitar el sonido de los pájaros. Es la emisión de los sonidos al imitar a la naturaleza la que marca una pauta comunicativa en el ser humano, quien con el paso del tiempo logra articular un lenguaje sofisticado con sonidos propios cargados de significantes que dan paso a la formación de la cultura (Cruz, 2011).

Esta complejidad en la creación de sonidos es la que permite el surgimiento de diferentes idiomas que lograran caracterizarse por medio de la musicalidad particular en cada uno de ellos, sonoridad identitaria, unificadora y formadora de diversidades 
culturales (Cruz, 2011; Abello y Ramos, 2009). Esto marca la música como el inicio del lenguaje, lenguaje que forma al sujeto y a la cultura en la que se encuentra inmerso.

\section{Historia de la música}

Como bien se menciona, el desarrollo de la música entre los seres humanos aconteció con el telón de fondo de los sonidos naturales del entorno y de su propio ser. Sin embargo, su desarrollo se ha ido transformando a través del tiempo y la historia, ajustándose a las necesidades contextuales, caracterizándose por ser siempre un componente común en las distintas culturas que han construido las sociedades.

Se considera que la prehistoria concluyó con el desarrollo de la escritura, y por tanto, también la música que se producía. La música de la antigüedad es el nombre con que se denomina la actividad musical realizada durante el Edad antigua. En los dibujos encontrados en los jarrones y paredes, se detallan instrumentos de viento con dos tubos, como los utilizados por los griegos, y gaitas antiguas. También se hallan escritos, como los de Aristóteles que describen técnicas musicales de la época, indicando algún tipo de polifonía (Hamel y Hurlimann, 1970).

En cuanto a tradiciones clásicas, se consideran tradiciones aprendidas, duraderas y trascendentes en muchas culturas como lo fue por ejemplo en la India, es una de las tradiciones musicales más antiguas del mundo. La civilización del Valle del Indo tiene esculturas donde se representan espectáculos de danza y aparecen instrumentos musicales antiguos, como la flauta de siete agujeros. Además, se han logrado recuperar varios tipos de instrumentos de cuerda y tambores (Hamel y Hurlimann, 1970).

La música clásica europea hace referencia a la música producida por las tradiciones artísticas en Europa, especialmente entre el año 1000 y 1900, si bien la denominación de "música clásica" se sigue aplicando a las composiciones de los siglos XX y XXI que surgen de esta tradición, la fundamentación teórica de esta tradición se desarrolló entre 1550 y 1825 (Honolka, 1968).

Otra de las grandes civilizaciones que han aportado a la música es la Antigua Grecia, principalmente los aportes del tradicional Teatro griego, en el que se presentaban en actos 
de entretenimiento y en celebraciones religiosas. Entre los instrumentos musicales que los acompañaban estaba el aulos de caña doble, y un tipo de lira, instrumento de cuerda pinzado: la cítara. En esta civilización la música tenía un papel importante dentro de la educación de los individuos, ya que se enseñaba desde los seis años. Además integraba conjuntamente, poesía, música, danza y gimnasia (Ojeade, 2011).

Posteriormente hace aparición la época del Renacimiento, en este periodo, los principales centros nobiliarios y las grandes catedrales se dotaron de capillas en las que se reunían compositores, cantores e instrumentistas. Cada centro procuraba, en la medida de sus posibilidades, los mejores músicos. Los principales géneros de la música sacra de la época eran la misa y el motete. La invención de la imprenta tuvo una gran importancia en la diseminación de los estilos musicales, y en la difusión de la música y el estilo francoflamenco por toda Europa, además contribuyó al establecimiento del primer estilo verdaderamente internacional de la música europea desde la unificación del canto gregoriano en la época de Carlomagno, 700 años antes (Massimo, 1985).

Los inicios de la ópera marcaron un paso importante dentro de la música, ya que fue uno de los movimientos más revolucionarios de la época se desarrollaría en Florencia durante los años 1570 y 1580, bajo el impulso innovador de la Camerata florentina. Sus miembros, descontentos con la música del momento, pretendían restaurar la música de la antigua Grecia. Las primeras óperas, escritas alrededor de 1600, también sirven para delimitar el final del renacimiento y el comienzo del Barroco musical (Hamel y Hurlimann, 1970).

En el Barroco, los grandes focos de música polifónica y concertando continuaron siendo las cortes reales y las casas nobiliarias, y los templos principales de las grandes ciudades europeas. Los instrumentos mayoritariamente utilizados eran el teclado, especialmente el clave, era el instrumento dominante, y con la llegada de la afinación temperada abrían posibilidades para tocar en todas las tonalidades. El bajo continuo es uno de los rasgos característicos del Barroco y era realizado de forma habitual por un teclado (clavecín, órgano, o en ocasiones un laúd), y un instrumento grave, como una viola da gamba o un fagot (Hill, 2008).

La música del Clasicismo se caracteriza por una una textura homofónica, el recurso frecuente a la melodía con acompañamiento, melodías que tendían a ser "cantables", frases simétricas, y estructuras formales cerradas y fuerza rígidas. Este periodo marcó un notable 
crecimiento de la música instrumental, con invenciones como el piano. La ópera se siguió desarrollando, esta vez en diferentes formatos, como la ópera bufa y otros géneros cercanas, algunos en las lenguas nativas de cada territorio (Honolka, 1968; Hamel y Hurlimann, 1970).

La música del Romanticismo se caracteriza por tener un vínculo con el resto de facetas del pensamiento y la cultura, principalmente la literatura y la filosofía. La composición emprende una búsqueda de expresividad y de emoción que lleva a una flexibilización de las formas musicales emanadas del Clasicismo (Massimo, 1985).

En la segunda mitad del siglo XIX se produjo una expansión en las dimensiones de la orquesta, y la consolidación del concierto como una actividad relevante en el ámbito cultural y social. Los grandes focos de producción musical son las grandes ciudades donde habita un público, generalmente burgués, donde se integra la asistencia a conciertos como un nuevo componente dentro de la música. En el siglo XX, se produce una revolución en las artes y principalmente en la música. La búsqueda de la libertad y la experimentación en la creación en el sentido más amplio del término llevó a la aparición de unos estilos musicales totalmente nuevos que desafiaban y, a menudo rompían las reglas musicales aceptadas en periodos anteriores. Fue clave la invención de instrumentos electrónicos y la posibilidad de grabar el sonido, representando una dimensión diferente tanto en el ámbito de la música llamada clásica, como en la popular. La confluencia de culturas generó una explosión artística y comercial de estilos musicales muy influyentes, como fue el jazz, y hacia los años 50 el rock y la música pop. La historia de la música en el siglo XX es una serie de intentos y experiencias que dio lugar a una serie de nuevas tendencias, técnicas y, en algunos casos, también la creación de nuevos sonidos, que contribuyen todos para que sea uno de los periodos más apasionantes de la historia música (Honolka, 1968; Fubini y Aranda, 2005).

La música analizada desde sus diversas manifestaciones a través de la historia, muestra cómo desde la musicalidad innata de nuestro entorno, de nuestro cuerpo, y por ello del propio lenguaje, se ha masificado y llevado a la construcción social y conjunta, a las culturas, modificándose y adaptándose a los significantes y necesidades de las civilizaciones. Apropiándose de ella y representando así a través del tiempo, historia, estatus, legados, religión, experimentación, revolución, expresión, unión, es decir, desde la 
naturalidad primitiva hasta las invenciones modernas, la música a pesar de su diversificación cultural, se sostiene de un único sentido, y es lo que se dice a través de ella.

\section{Los componentes de la música}

Para comprender de manera más completa este tipo de arte, es necesario tener claro que la música posee elementos específicos que la construyen, haciendo de la música lo que se conoce en sus múltiples variaciones.

Se debe de entender que no todo sonido es música, que la música requiere una manera determinada de ser hecha con esos elementos específicos, como indica Cruz (2011), la música es un lenguaje en cierta medida matemático, que estructura valores (notas musicales), repeticiones de acorde, escalas y otros, así como el hecho de poseer una duración. Aunado a lo anterior, se dice entonces que la música es un lenguaje con un sistema de códigos específicos, con letras y signos, que es además representativo (informado por la palabra) y es normativo, pues posee reglas y principios para su uso, aprendizaje y comprensión (Rodriguez Fornoza, 2016).

Como lenguaje, la música se asemeja a los sueños dentro del ejercicio psicoanalítico, puesto que solamente se puede hablar de su interpretación, se le pone nombre o se reconstruye lo innombrable y es limitado a la subjetividad y significado que cada quien le brinde. En su composición además de las estructuras que la componen, se da la repetición de eso que no para de no ser escrito (Cruz, 2011).

Ahora bien, entre los elementos que comprende la música, se encuentran la armonía, la melodía, los tonos, el ritmo y los silencios, los cuales serán brevemente rescatados a continuación.

\section{Armonía}

La armonía musical hace referencia a la sucesión de distintos sonidos en un mismo momento, o a la combinación de notas musicales que se emiten al mismo tiempo. No obstante, el que exista armonía dentro de la música implica no solo el hecho de la 
simultaneidad de notas en un tiempo determinado, sino, que estos sonidos deben entonar, es decir deben de complementarse de una manera que encajen unos con los otros (Martínez y García, s.f).

Rodríguez Penagos (2007) destaca en la ejecución de la música, como el instrumento es una extensión del cuerpo del músico, apropiándose de la materialidad del instrumento y hacerlo parte del cuerpo mismo, de alguna manera, realizando una unión entre cuerpo e instrumento de manera que se complementan y encajan de forma armónica para fusionarse. Garzarelli (2011) por su parte agrega que la armonía con respecto al ser humano, corresponde a la razón.

\section{Melodía}

La melodía por su parte se realiza a partir de la organización de un sonido tras otro, de forma que cada uno posee una altura y duración específicas, es decir, "se da un movimiento de sonidos a otros de manera fluida" (Martínez y García, s.f, p. 3).

La melodía se hace presente en la música como el elemento afectivo de la misma, ya que involucra elementos que exponen la vida sensorial, afectiva y pasional de quien crea la música y de quien la escucha. Asimismo, la melodía es bidimensional, pues esta intrínsecamente conlleva el ritmo (Alvarado, 2013; Garzarelli, 2011).

En relación con el cuerpo, la melodía se lleva dentro del lenguaje hablado, con menos regulaciones que en la música por supuesto, pero existente, y es el Otro quien regula la melodiosidad en conjunto con los otros elementos (Cruz, 2011). Entonces, la melodía en la música se puede comparar con la continuidad utilizada en el lenguaje (tonos seguidos de forma fluida que forman palabras, preguntas, frases y otros) (Rodríguez Fornoza, 2016).

\section{Tonalidades-Notas}

Los tonos son los diferentes sonidos que se escuchan dentro de una pieza musical, son el conjunto de esos tonos lo que hace posible que se creen las piezas musicales. Al hablar de 
los tonos o las notas, es importante mencionar que estos contienen una frecuencia, que determina la altura de ese tono o nota (graves o agudos) (Martínez y García, s.f).

Así mismo, como se mencionó con la melodía Cruz (2011) indica que el tono también forma parte de la reproducción de sonidos con el cuerpo, en donde en el habla de forma evidente se pueden acentuar palabras, o letras, cambiar el timbre de voz, de forma que se adecue al momento y sea comprensible, se da una modificación de lo expresado por medio de las notas al igual que en la música.

\section{Ritmo}

Ahora bien, el ritmo de acuerdo a Lobo (2011), es el que genera la organización en el tiempo de las notas que se perciben, es el rito quien dicta la forma de distribuir los sonidos, acentos y pausas, es la "ordenación del movimiento". En otras palabras, el ritmo tiene la función de organizar toda la pieza musical, otorgando el movimiento, la sincronicidad.

El ritmo se muestra entonces como un elemento fundamental en la música, pero asimismo, forma parte de la "musicalidad" del cuerpo de diversas maneras. De acuerdo con lo indicado por el autor anterior, el ritmo forma parte de las funciones vitales como la respiración, los latidos del corazón, el caminar, y en general todos los movimientos son marcados por el ritmo. Garzarelli (2011) indica que en cuanto a cuestión de música el ritmo se une al cuerpo.

Vernia (2014) agrega que el ritmo, en el cuerpo se percibe a través del pulso y el latir del corazón, donde este se convierte en un latir constante regular o irregular, que también puede ser fuerte o débil. Así también, este llega a dar una conciencia del movimiento rítmico, lo que puede provocar el funcionamiento adecuado del sistema nervioso, igualmente, la coordinación, psicomotricidad de la persona, permitiendo una mayor conciencia de la parte corporal.

Desde distintas posturas se plantea el cuerpo como instrumento que percibe el sonido y que logra expresar dicha percepción, en donde la música se convierte en quien da un sentido a la acción motriz del ser humano, recalcando además que el aprendizaje musical se fundamenta en diversos elementos siendo el ritmo de gran importancia, en donde el cuerpo 
puede ser un recurso didáctico (Vernia, 2014). Cabe destacar que el ritmo de la palabra funciona en relación con el ritmo musical (Rodríguez Fornoza, 2016), de manera que lo hablado puede constituirse a partir de un registro que cumple con algunos elementos propios de la música, como lo es precisamente el ritmo.

\section{Silencios}

Como elemento fundamental en la música se encuentra el silencio, ya que este proporciona las bases para que esta sea construida, donde sin tiempo o ritmo no hay música, más sin silencio tampoco podría existir. El silencio está ausente de sonido mas no ausente de significante, ya que este puntualiza esos que no se ha expresado aún, algo que se va a expresar o no, algo que produce el mismo sonido al escucharse (Cruz, 2011).

De la misma forma en el análisis psicoanalítico, el silencio forma o puntualiza diversos aspectos, como el acallar discursos, acciones, pensamientos, así como da pie a la palabra, a la voz del analista y de la persona que asiste a análisis (Cruz, 2011), da pie al dolor pues toca los límites de la palabra, de que es imposible de decir, de la expresión de la imposibilidad (Hounie, s.f).

Colom (2013), indica que en la música el silencio no es el opuesto al sonido, sino que se pone en conjunto con este, es el silencio quién da lugar a la existencia del ritmo, de la melodía, de la armonía, de la música, gracias al silencio el sonido es diferenciado, es lo que permite asimismo la sonoridad armónica del habla.

\section{Música, afectos, y cuerpo}

Como se ha mencionado en apartados anteriores, la música es un arte inherente al ser humano ya que esta ha estado presente desde épocas perinatales en donde, por ejemplo, mediante el grito se expresa la separación de la madre siendo este un canto de denuncia de su incompletud, es aquí en donde se expresa la prehistoria de un cuerpo y un sujeto (Gambini, s.f). 
El contacto con la música, con lo creativo, permite no sólo encontrarse con ritmos o melodías, sino con afectos que producen una vivencia que atraviesa el cuerpo que va generando viajes, ideas, sentires, los cuales quedan impregnados en los registros del sujeto creándose cadenas de significantes que hacen que se dé una vivencia afectivo-corporal de esas vibraciones que escuchamos, convirtiendo al cuerpo en un significante, en un cuerpocuerda (Gambini, s.f). Es decir, el despertar de la fusión primitiva ante la música hace que el cuerpo tenga su propia forma acústica (Rodríguez, 2007).

En todas las ocupaciones de la vida en que la belleza ha sido la inspiración, en el que el vino divino ha sido vertido, hay música. Pero también se compone una música con las penas, con el padecimiento, con eso que queda vibrando, molestando, trancando, resonando, con la rabia, la tristeza, la nostalgia (Khan, 1995 en Gambini s.f, p.1).

El cuerpo-cuerda vibra, y produce movimientos dependiendo del afecto que se exprese, o que se sienta, mostrando una gama de tonalidades afectivas que de una u otra manera permean la percepción de la vida en cuanto a recuerdos, discursos, afectos, vibraciones que van mostrando algo de lo que, en el cuerpo, necesita ser hablado, sin importar si se da con tristeza, alegría o furia (Gambini, s.f).

Estas vibraciones pueden sentirse en una parte específica del cuerpo, pero en realidad el cuerpo en su totalidad es capaz de ser afectado y afectar, sintiéndose las vibraciones y movimientos en el sujeto, así como en sus conexiones con los otros y con el Otro. Así que, tanto el sujeto como las relaciones sociales, impregnarán de afectos a ese cuerpo que de una u otra manera crean y encuentran ruidos que desarmonizan la musicalidad del cuerpo. Lo cual se puede relacionar a lo psicosomático, en tanto al cuerpo que sufre o manifiesta un malestar debido a esas vibraciones que se contienen, que se reprimen (Gambini, s.f). 


\title{
La música y lo Real, Simbólico, Imaginario (RSI)
}

Antes de hablar de los tres registros, es relevante citar a dos de las figuras más emblemáticas del psicoanálisis. La primera cita es de Sigmund Freud, y es tomada de su escrito El Moisés de Miguel Ángel:

Las obras de arte, empero, ejercen sobre mí poderoso influjo, en particular las creaciones poéticas y escultóricas, más raramente las pinturas. Ello me ha movido a permanecer ante ellas durante horas cuando tuve oportunidad, y siempre quise aprehender a mi manera, o sea, reduciendo a conceptos, aquello a través de lo cual obraban sobre mí de ese modo. Cuando no puedo hacer esto - como me ocurre con la música, por ejemplo-, soy casi incapaz de obtener goce alguno. Una disposición racionalista o quizás analítica se revuelve en mí para no dejarme conmover sin saber por qué lo estoy, y qué me conmueve (Freud, 1914, p. 217).

La segunda cita, corresponde a Jacques Lacan, de su Seminario XX Aun:

\begin{abstract}
Alguna vez -no sé si tendré tiempo algún día- habría que hablar de la música, al margen. Por lo tanto, solamente hablo de cuanto se ve en todas las iglesias de Europa, cuanto se cuelga en las paredes, se desmorona, deleita, delira. Lo que hace un rato llamé obscenidad, pero exaltada (Lacan, 1972-1973, p. 101).
\end{abstract}

De esta manera se referían Freud y Lacan respecto a la música, el primero se presenta como un ser que no es conmovido, que no es atraído, un no apasionado de la música. El segundo, se muestra distante, "al margen" como él mismo lo dice, alejado de ese tema.

Esto hace que surja una pregunta, ¿por qué esa amusía? O dicho de una forma más sencilla, ¿por qué la carencia de música en esta figuras del psicoanálisis? La respuesta es en realidad sencilla. La razón por la que ni Freud, ni Lacan, ni sus discípulos, se dieron a la tarea de acercarse, siquiera, al análisis de la música, es debido a que este es imposible. Posiblemente para estas figuras esto no era sabido, ni consciente, sin embargo ahora podemos decir que la música posee el carácter de ser in-analizable. 
Esto es debido a que la música se encuentra estrechamente relacionada o ligada al registro de lo Real. La música es prácticamente puro Real, ya que el Imaginario y el Simbólico han sido sustraídos de la misma. Esta forma de arte, tiene la peculiaridad de no poseer una idea de representación (a esto nos referimos con el Imaginario y el Simbólico sustraídos). Al estar tan estrechamente ligada a lo Real, la música adquiere la característica de inalcanzable, o imposible de alcanzar/tocar. Aún para el intérprete más habilidoso, o con más experticia, va a ser imposible tocar o interpretar una obra musical dos veces de la misma manera (Morales, 2013). Debido a la implicación de los afectos que se explicó en el apartado anterior.

Sin embargo, pese a lo in-analizable de la música, y a lo inalcanzable, podemos acercarnos a la misma. Esto debido a ese Imaginario y Simbólico sustraídos. Esto da pie para explicar estos dos registros.

El registro de lo Imaginario en la música corresponde al sentir, a la emocionalidad, y todos los afectos que son desencadenados por la misma. Los recuerdos que son evocados por la música, y que a su vez traer consigo esos sentimientos (Morales, 2013).

Por su parte, lo Simbólico es el lenguaje de la música, el lenguaje en la música, y el lenguaje que evoca la música. Es decir, lo primero se refiere al lenguaje musical en sí, a la transliteración de la música a la grafía. Lo segundo corresponde a la letra presente en la música, y que hace que pase a ser canción. Lo tercero finalmente, sería la verbalización del Imaginario, o dicho de otro modo, el hablar sobre los afectos, recuerdos, emociones, que la música evoca, o hace que se presenten (Morales, 2013).

Parrabera (2002) explica los tres registros en la música, relacionando el ternario RSI con tres personajes que, de una u otra forma, son parte de esta manifestación del arte. Para la autora ya mencionada, el RSI estaría representado en la música por la tríada conformada por el compositor, el intérprete, y el oyente.

En donde, lo Simbólico correspondería a la figura del Compositor, ya que este translitera la música, plasmándola en un papel, convierte ese sonido en una grafía, en el lenguaje musical de negras, redondas, blancas, corcheas, silencios de negra y de redonda, de claves de sol y de fa, de puntillos, de bemoles y sostenidos, en todo un mundo lingüístico que representa a la "música escrita" (Parrabera, 2002). 
Así mismo, lo Real haría referencia al Intérprete, ya que este toma esa "música escrita", y la interpreta, o lo trata de hacer. Decimos trata debido a que, por su carácter de inalcanzable, la música que es interpretada nunca será la misma que la figura anteriormente mencionada compuso. Incluso el intérprete no va a interpretar la misma obra musical de la misma manera aunque lo haga repetidas veces, como ya se mencionó (Parrabera, 2002).

Finalmente, lo Imaginario correspondería al Oyente, pues es a partir de este que se puede crear el análisis de la música escuchada. Es la persona que escucha la música quien tiene la capacidad de imaginar, de sentir, de pensar esa música, y es a partir de esto que se realiza el análisis de lo que se escucha y no de la música en sí (Parrabera, 2002).

\section{Conclusiones}

Es la música por lo anteriormente explicado, un factor que no solamente se encuentra en el medio que rodea al ser humano desde el inicio de su existencia, sino que forma parte de la persona como tal desde una cuestión innata, del comunicar algo, incluso desde la parte más pulsional. Se toma entonces la música como una forma de arte expresado a través del cuerpo, "musicalidad biológica", de manera que instintivamente, como raza, influye en la sobrevivencia del ser humano, implicada en los procesos de adaptación, de relación con el otro y que gracias a esta se da forma y guía al lenguaje, es decir le antecede.

Así mismo, la música marca épocas, contextos, historia, cultura, estatus, herencia, desde el conocimiento de la misma hasta la actualidad, ayudando a la expresión y diferenciación de procesos que van a nivel cultural, regional, de relación con el otro y a nivel personal, este último mediante lo que se carga, lo que se expresa, lo que en cada quien la música evoca y significa.

Cabe mencionar, que en el proceso de análisis se da paso a un ambiente de "procesos musicales" entre el analista y analizante, se crea una escucha de los sonidos emitidos por ese instrumento del cuerpo, con melodía, armonía, tonalidades, ritmo y silencios que se entrelazan para permitir escuchar y escucharse, en donde al igual que la música por sí sola genera y transmite, el silencio lo hace para develar lo que se desconoce que se conoce, lo que provoca emociones (dolor, alegría, tristeza, soledad, sorpresa, y otros), y es tanto 
analista como analizante, quienes comprenden esa musicalidad en el proceso, pues son dueños de la misma en distintos momentos.

Siguiendo esta misma línea, analista y analizante llegan a comprender esa musicalidad, y a comprenderse en esa musicalidad, debido a la interrelación inconsciente que se da, aunque suena cacofónico, de inconsciente a inconsciente. Son las subjetividades, esos recuerdos, esos afectos, emociones y demás, que hacen que tanto el Imaginario del analista como del analizante, establezcan este proceso de entendimiento, mediante la verbalización, la parte más Simbólica de ambos, y que tienen como punto en común eso Real, que es la música, y la musicalidad del y en el proceso.

\section{Bibliografía}

Abello, S. y Ramos, R. (2009). Lenguaje y musicalidad: su relación y sus implicaciones en la adquisición de una segunda lengua. (Tesis de pregrado). Pontificia Universidad Javeriana, Bogotá, Colombia.

Alvarado, R. (2013). La música y su rol en la formación del ser humano. Universidad de Chile. Recuperado de: http://repositorio.uchile.cl/bitstream/handle/2250/122098/La_musica_y_su_rol_en_1 a_formacion_del_ser_humano.pdf?sequence=1

Colom, A. (2013). Sentido, significación y ruido. Recuperado de: https://www.google.com/url?sa=t\&rct=j\&q=\&esrc=s\&source=web\&cd=1\&cad=rja \&uact=8\&ved=0ahUKEwisrZjVxNTQAhVERyYKHcUrB_UQFggaMAA\&url=htt p\%3A\%2F\%2Fwww.psicoanalisisysociedad.org\%2FTextos\%2F2013\%2FSentidoAntonio\%2520Colom.doc\&usg=AFQjCNGjTlamvvIKkaFvVqMsVhEJ50IREg\&sig 2=ldACu5TQ7Wk1mqnm4eZTeA\&bvm=bv.139782543,d.eWE

Cruz, M. (2011). Algunas cuestiones sobre la composición lírica y musical en psicoanálisis. Errancia, Revista de Psicoanálisis, Teoría Crítica y Cultura, 1. Recuperado de: http://www.iztacala.unam.mx/errancia/v1/PDFS_1/CAIDAL4_ALGUNASCUESTI ONESSOBRELACOMPOSICIONMUSICAL.pdf 
Destefanis, O. (2016). Música y psicoanálisis. Cuestiones de oreja. Universidad John F. Kennedy. Recuperado de: https://www.kennedy.edu.ar/wp-content/uploads/bsk-pdfmanager/2016-09-19_118.pdf

Freud, S. (1914) El Moisés de Miguel Ángel En Obras Completas, Tomo XIII, pp. 213242. Buenos Aires: Amorrortu Editores.

Fubini, E., \& de Aranda, C. G. P. (2005). La estética musical desde la Antigüedad hasta el siglo $X X$. Alianza editorial. Recuperado de https://dialnet.unirioja.es/servlet/libro?codigo=292624

Gambini, M. (s.f.) Un cuerpo, una cuerda, un significante. Universidad de La República. Recuperado de http://www.academia.edu/25894048/Un_cuerpo_una_cuerda_un_significante

Garzarelli, J. (2011). La música como lenguaje universal. Encuentro Paranaense, Congreso Brasileño de Psicoterapias Corporales, XVI, XI. Recuperado de: http://www.centroreichiano.com.br/artigos/Anais\%202011/GARZARELLI,\%20Jor ge\%20G.\%20La\%20musica\%20como\%20lenguaje\%20universal.pdf

Hamel, F., Hurlimann, M. (1970). Enciclopedia de la música. Barcelona: Gribaljo. Recuperado de ftp://ftp.puce.edu.ec/Facultades/CienciasEducacion/ModalidadSemipresencial/Histo ria\%20de\%20la\%20M\%C3\%BAsica\%20Universal-Luciano\%20Carrera.pdf

Hill, J. W. (2008). La música barroca (Vol. 3). Madrid: Ediciones AKAL. Recuperado de https://books.google.co.cr/books?hl=es\&lr=\&id=hqtG10rjQsEC\&oi=fnd\&pg=PA17 $\& d q=$ musica + del+barroco $\&$ ots=36oYxDOAkT $\&$ sig=ifE66sm3k5730CcNDyTZ9u MC44\&redir_esc=y\#v=onepage \&q=musica\%20del\%20barroco\&f $=$ false

Honolka, K. (1968). Historia de la música. Madrid: Editorial EDAF. Recuperado de ftp://ftp.puce.edu.ec/Facultades/CienciasEducacion/ModalidadSemipresencial/Histo ria\%20de\%20la\%20M\%C3\%BAsica\%20Universal-Luciano\%20Carrera.pdf

Hounie, A. (s.f.). La subjetividad comprometida: fragmentos para una estética del dolor. Lacan, J. (1972-1973). Seminario XX Aún. Buenos Aires: Editorial Paidós. 
Lobo, E. (2011). Mi Cuerpo, Mi entorno, Mi música. Ensamble de percusión corporal y cotidiáfonos (Tesis de licenciatura en Música). Universidad Industrial de Santander, Bucaramanga: Colombia. $\quad$ Recuperado de: http://repositorio.uis.edu.co/jspui/bitstream/123456789/9120/2/142039.pdf

Martínez, T., y García, R. (s.f). Armonía musical. Definición e Historia. Recuperado de: https://mat-web.upc.edu/people/xavier.gracia/musmat/treballs/GarMar.armonia.pdf

Massimo, M. (1985). Historia de la música. Barcelona: Bruguera.

Morales, F. (2013). La música y su cercanía a lo real. Revista Borromeo. 4, pp. 545-560. Recuperado de http://borromeo.kennedy.edu.ar/Artculos/MoralesMontielmusicayreal.pdf.

Parrabera, S. (2002). Música y Psicoanálisis. Rachmaninoff. Trama y fondo: Revista de $\begin{array}{lllll}\text { cultura. } & 13, & \text { pp. } & \text { 52-62. }\end{array}$ https://dialnet.unirioja.es/servlet/articulo?codigo $=2248533$.

Rodriguez Fornoza, L. (2016). La música como lenguaje y como medio de expresión. Publicaciones Didácticas. 69, 445-446. Recuperado de: http://www.seindor.com/publicacionesdidacticas.com/hemeroteca/articulo/069056/a rticulo-pdf

Rodríguez Penagos, J. (2007). De musas y sirenas. Apuntes sobre música y psicoanálisis. Revista Intercontinental de Psicología y Educación, 9 (2), p. 85-92. Recuperado de: http://www.redalyc.org/articulo.oa?id=80290206

Ojeda, J. L. E. (2011). Una aproximación a la música griega antigua. Thamyris, nova series: Revista de Didáctica de Cultura Clásica, Griego y Latín, (2), 141157.Recuperado de http://www.thamyris.uma.es/thamyris2/espinar.pdf

Vernia, A. (2014). El ritmo a través del cuerpo como herramienta de aprendizaje musical. La competencia rítmica. Quaderns digitals, 78. Recuperado de: http://www.quadernsdigitals.net/index.php?accionMenu=hemeroteca.VisualizaArtic uloIU.visualiza\&articulo_id=11384\&PHPSESSID $=$ e2352085b9de4f4f26c550c8057 $\underline{9518}$. 